Supporting information

\title{
Improving High-current-density Performance of PEMFC through Much Enhanced Utilization of Platinum Electrocatalysts on Carbon
}

Fengjuan Zhu, ${ }^{\dagger}$ Liuxuan Luo, ${ }^{\dagger}$ Aiming Wu,${ }^{\dagger}$ Chao Wang, ${ }^{\dagger}$ Xiaojing Cheng,,${ }^{\dagger}$ Shuiyun Shen,${ }^{\dagger}$ Changchun $\mathrm{Ke}, \stackrel{\dagger}{ }$ Hong Yang,,$\stackrel{\dagger}{ }$ and Junliang Zhang*,†

†nstitute of Fuel Cells, MOE Key Laboratory of Power Machinery \& Engineering, Shanghai Jiao Tong University, Shanghai 200240, PR China

\#Department of Chemical and Biomolecular Engineering, University of Illinois at Urbana-Champaign, 206 Roger Adams Laboratory, MC-712, 600 South Mathews Avenue, Urbana, IL 61801, USA

* CORRESPONDING AUTHOR

* Email address: junliang.zhang@sjtu.edu.cn 
Figures

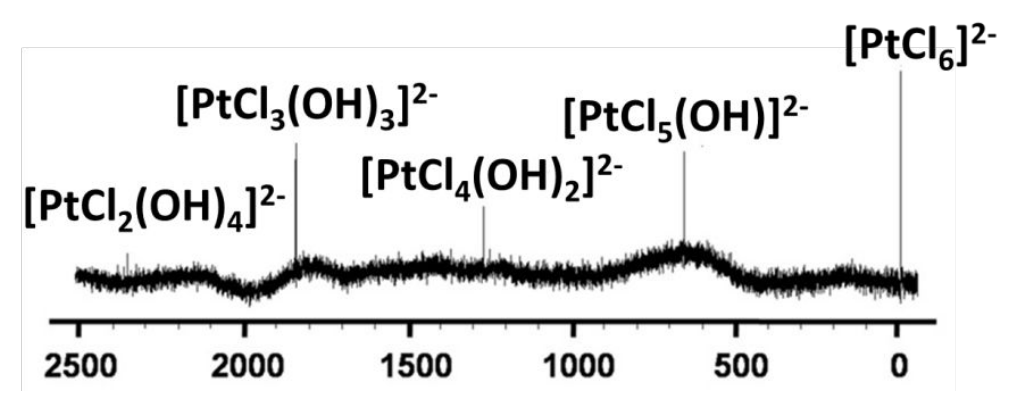

Figure S1. ${ }^{195} \mathrm{Pt} \mathrm{NMR}$ spectrum for the products from heating the mixed solution of $\mathrm{H}_{2} \mathrm{PtCl}_{6}$ and $\mathrm{NaOH}$ at $100{ }^{\circ} \mathrm{C}$ for $3 \mathrm{~h}$

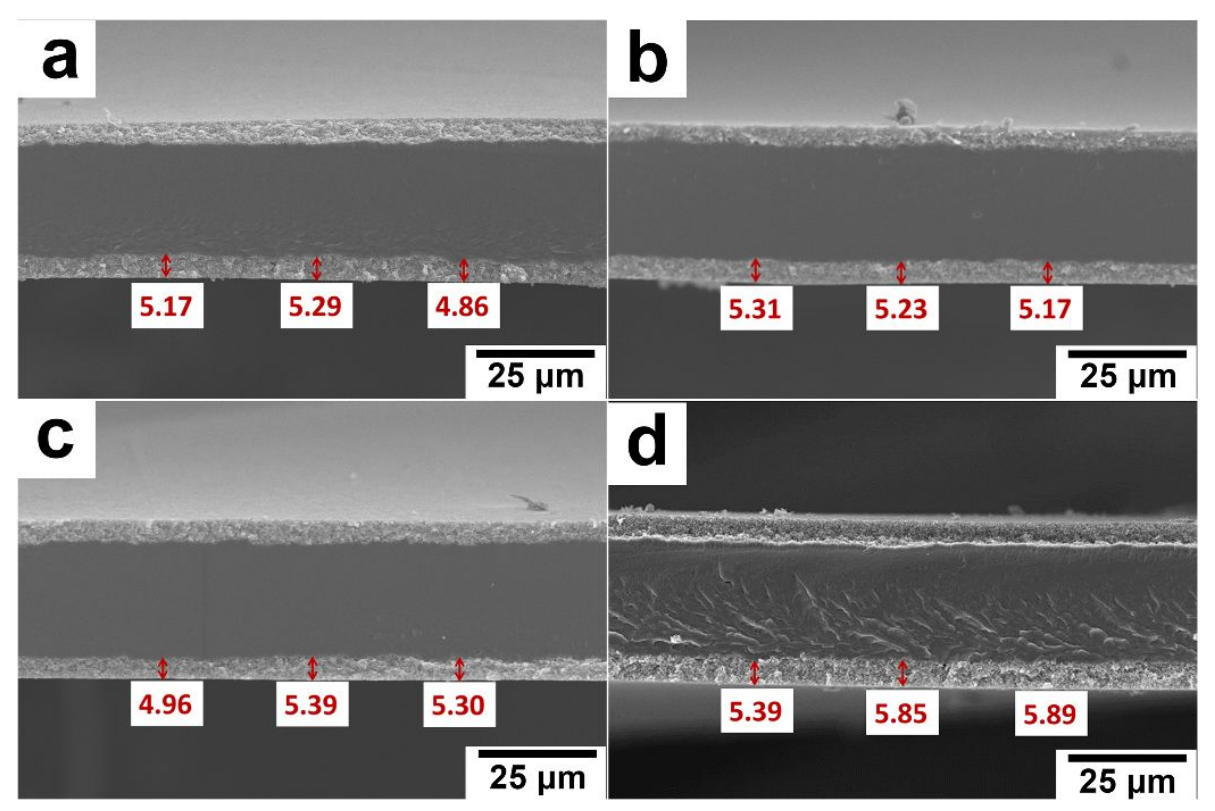

Figure S2. Freeze fracture SEM cross-sectional analysis of thickness: Pt/VC(I) (a), Pt/VC(II) (b), Pt/VC(III) (c) and Commercial catalyst (d). 


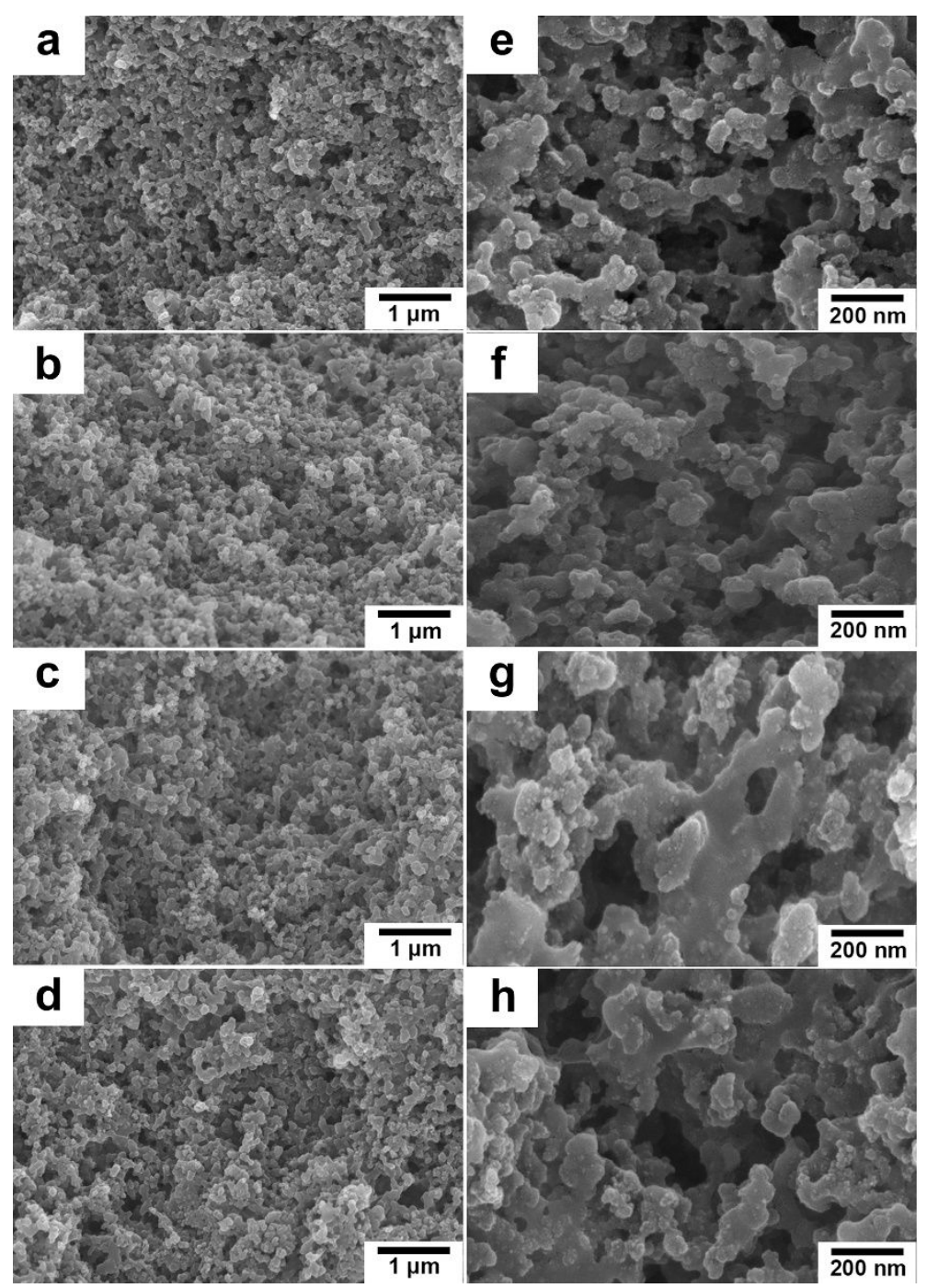

Figure S3. SEM images for the cathodic layers with different catalysts: Pt/VC(I) (a, e), Pt/VC(II) (b, f), Pt/VC(III) (c, g) and Commercial catalyst (d, h). 